\title{
Adequação da contagem de células somáticas e da contagem bacteriana total em leite cru refrigerado aos parâmetros da legislação
}

\author{
[Suitability of somatic cell count and total bacterial count in raw refrigerated \\ milk to legislation standards] \\ G.A. Bozo ${ }^{1}$, L.C.A. Alegro ${ }^{1}$, L.C. Silva ${ }^{1}$, E.H.W. Santana ${ }^{1 *}$, W. Okano ${ }^{1}$, L.C.C. Silva ${ }^{2}$ \\ ${ }^{1}$ Universidade Norte do Paraná - Londrina, PR \\ ${ }^{2}$ Universidade Estadual de Londrina - Londrina, PR
}

\begin{abstract}
RESUMO
O objetivo deste trabalho foi adequar a qualidade do leite cru refrigerado de cinco propriedades leiteiras aos parâmetros microbiológicos e de contagem de células somáticas (CCS) estabelecidos pela legislação estadual do Paraná. As propriedades leiteiras estudadas foram monitoradas durante sete meses após a implantação de boas práticas de ordenha e de recomendações quanto ao tratamento de mastites e à manutenção e higienização de equipamentos de ordenha. Antes da adoção das recomendações, a contagem bacteriana total (CBT) média era de $1,36 \times 10^{6} \mathrm{UFC} / \mathrm{mL}$ e a CCS média, de $1,87 \times 10^{6} / \mathrm{mL}$. Todas as propriedades atingiram os padrões estabelecidos para CBT, com redução média de $93,4 \%$. A redução de CCS foi, em média, 74,3\%. Apenas três propriedades atingiram os valores estabelecidos para CCS. As demais atingiram valores muito próximos ao limite. A adequação aos padrões de CBT e CCS gerou aumento na renda mensal, em razão do pagamento por qualidade do produto, entre $\mathrm{R} \$ 120,00 \mathrm{e}$ $\mathrm{R} \$ 828,00$, de acordo com a produção de cada propriedade.
\end{abstract}

Palavras-chave: leite, qualidade, manejo de ordenha, equipamento

\begin{abstract}
The aim of this work was to adequate raw refrigerated milk quality of five dairy farms to microbiological and somatic cell count (SCC) standards established by Paraná state legislation. The dairy farms were monitored during seven months after the implementation of good milking practices and recommendations regarding mastitis treatment, and milking equipment maintenance and hygiene. Before the adoption of recommendations, the average total bacterial count (TBC) was $1.36 \times 10^{6} \mathrm{CFU} / \mathrm{mL}$ and average SCC was $1.87 \times 10^{6} \% \mathrm{~mL}$. All farms reached established standards for TBC, originating an average reduction of 93.4\%. Average SCC reduction was $74.3 \%$. Only three farms reached established values for SCC. The remaining reached values near the limits. The suitability of TBC and SCC produced an increase in the monthly income due to payment quality reward of the dairy product, between $R \$ 120.00$ and $R \$ 828.00$, according to each farm production.
\end{abstract}

Keywords: milk, quality, milking management, equipment

\section{INTRODUÇÃO}

O Brasil é o quinto maior produtor mundial de leite, com produção de 29,948 mil toneladas no ano de 2010 (FAO, 2009; USDA, 2011). O Paraná é o terceiro maior produtor nacional, com 3,339 milhões de litros anuais (IBGE, 2009). A qualidade do leite produzido, contudo, apresenta problemas, como a alta contagem bacteriana total (CBT) e a alta contagem de células somáticas (CCS) (Santana et al., 2001; Fagan et al. 2005; Nero et al., 2005; Beloti et al., 2011; Silva et al., 2011).

Recebido em 14 de outubro de 2011

Aceito em 8 de outubro de 2012

*Autor para correspondência (corresponding author)

E-mail: elsahws@hotmail.com 
O Programa Leite das Crianças (Paraná, 2009), criado com o objetivo de reduzir a desnutrição infantil em famílias com baixa renda per capita mensal, fomenta o desenvolvimento das cadeias locais e regionais de leite, por meio do aumento na demanda e do estabelecimento de parâmetros mais rígidos de qualidade. $\mathrm{O}$ programa estabelece requisitos mínimos de qualidade para o leite cru, como contagem bacteriana total (CBT) máxima de $500 \mathrm{mil} \mathrm{UFC/mL} \mathrm{e} \mathrm{contagem}$ de células somáticas (CCS) máxima de 500 mil $\mathrm{CS} / \mathrm{mL}$ de leite. Esses parâmetros são mais rígidos que os estabelecidos pela legislação federal até janeiro de 2012 (Brasil, 2002; 2011), que permite CBT e CCS máximas de 750 $\mathrm{mil} / \mathrm{mL}$.

As medidas higiênicas adotadas nas propriedades rurais durante a obtenção do leite são fundamentais para se obter um produto de alta qualidade com baixa contagem bacteriana (Philpot e Nicherson, 2002). O estabelecimento de um programa de qualidade do leite eficiente requer, necessariamente, o treinamento dos ordenhadores sobre o correto funcionamento e manutenção dos equipamentos de ordenha, assim como a limpeza e higiene deles e a aplicação de boas práticas de ordenha (Santos e Fonseca, 2007).

O objetivo deste trabalho foi buscar adequar a qualidade do leite cru refrigerado de propriedades leiteiras aos parâmetros de CBT e CCS estabelecidos pela legislação estadual, por meio da implantação de boas práticas de ordenha, do monitoramento da sanidade e do tratamento da glândula mamária e, ainda, da manutenção e higienização dos equipamentos de ordenha.

\section{MATERIAL E MÉTODOS}

O trabalho foi desenvolvido no período de janeiro a agosto de 2010. Inicialmente, foram feitos o levantamento das práticas de ordenha realizadas e a avaliação da CBT, CCS, sanidade da glândula mamária, bem como a pesquisa e o isolamento de agentes etiológicos responsáveis pela mastite. Após a avaliação inicial, foram sugeridas mudanças no manejo de ordenha, no tratamento dos animais e na manutenção dos equipamentos de ordenha. $\mathrm{O}$ impacto das mudanças foi avaliado por meio do acompanhamento da CBT e da CCS do leite cru refrigerado produzido pelas propriedades durante um período de sete meses.

Foram selecionadas cinco propriedades leiteiras, que não se enquadravam nos parâmetros de CCS e CBT estabelecidos pelo Programa Leite das Crianças (Paraná, 2009), localizadas no município de Pitangueiras, Paraná. A produção leiteira dessas propriedades era destinada a um laticínio local que praticava o pagamento por qualidade. $\mathrm{O}$ rebanho leiteiro dessas propriedades era constituído por animais da raça Holandesa, com média de cinco lactações, em sistema de semiconfinamento e com bezerros alimentados separadamente em baldes individuais. As instalações eram simples, sem pavimentação dos currais de espera. Todas as propriedades avaliadas usavam ordenha mecânica do tipo balde ao pé e realizavam duas ordenhas diárias, com armazenamento em tanque de expansão (Tab. 1).

Tabela 1. Características de produção das cinco propriedades leiteiras localizadas em Pitangueiras, Paraná, acompanhadas no período de janeiro a agosto de 2010

\begin{tabular}{lcccccc}
\multicolumn{1}{c}{ Características } & $\mathrm{A}$ & $\mathrm{B}$ & $\mathrm{C}$ & $\mathrm{D}$ & $\mathrm{E}$ & Média \\
\hline $\mathrm{N}^{\circ}$ de vacas em lactação & 19 & 17 & 28 & 20 & 13 & 19,4 \\
Produção diária média (L) & 400 & 300 & 570 & 430 & 200 & 380 \\
Produção diária/animal (L) & 21 & 17,6 & 20,3 & 21,5 & 15,3 & 19,1 \\
\hline
\end{tabular}

Foi acompanhada e registrada, por meio da aplicação de questionário, a rotina de ordenha em cada propriedade. Os itens avaliados foram: uso do teste da caneca de fundo preto; realização do CMT; realização de pré e pós-dipping (produto e concentração utilizados; tempo de contato da solução com os tetos; secagem dos tetos antes do inicio da ordenha (papel ou pano); funcionamento e manutenção da ordenhadeira; protocolo utilizado na higienização de utensílios e equipamentos de ordenha (produto, concentração da solução, frequência da prática e temperatura da água utilizada); produção diária de leite, tipo de alimentação e fármacos utilizados no tratamento da mastite clínica e na secagem dos animais. 
Foi realizado o California Mastits Test (CMT) em 97 animais em lactação. Os quartos que apresentaram mastite - duas a três cruzes no CMT - foram higienizados com álcool $70 \%$, desprezando-se os três primeiros jatos de leite, e, em seguida, procedeu-se à coleta de uma amostra de $25 \mathrm{~mL}$ de leite em tubo de ensaio estéril. As amostras de leite foram acondicionadas em caixa isotérmica com gelo reciclável $\left(4^{\circ} \mathrm{C}\right)$ e encaminhadas para um laboratório escola de microbiologia, onde foi realizada cultura e antibiograma para identificação do agente causador da mastite e o fármaco mais indicado para seu controle.

As amostras de leite foram semeadas em ágar sangue de ovino a $5 \%$ e foram incubadas em estufa a $37^{\circ} \mathrm{C}$ por $24 / 48$ horas. As colônias foram submetidas à coloração de Gram e a provas bioquímicas para identificação de gênero e espécie: Staphylococcus spp., S. pyogenes, Streptococcus spp., $S$. agalactiae, $S$. dysgalactiae, S.uberis, Enterecoccus spp., Escherichia coli (Koneman et al., 1999), Staphylococcus aureus (Holt et al., 1994); Pseudomonas spp. (Hirsh e Zee, 1999).

A contagem de células somáticas e a bacteriana total nas propriedades estudadas foram realizadas pelo laboratório da Associação Paranaense de Criadores de Bovinos da Raça Holandesa, credenciado no Programa de Análise de Rebanhos Leiteiros do Paraná. A CBT e a CCS foram realizadas nas cinco propriedades estudadas mensalmente, no período de janeiro a agosto de 2010.

\section{RESULTADOS E DISCUSSÃO}

A avaliação realizada por meio de questionário e acompanhamento da ordenha demonstrou que os ordenhadores não possuíam conhecimento adequado quanto ao correto funcionamento e manutenção dos equipamentos de ordenha, dificultando, assim, o processo de utilização e higienização desses equipamentos.

Quanto às boas práticas de ordenha, todas as propriedades apresentaram problemas. A prática do pré-dipping era realizada com água, e a secagem com toalha de pano coletiva. $\mathrm{O}$ teste de caneca de fundo preto não era realizado e os primeiros jatos de leite eram desprezados no chão. O pós-dipping não era realizado e não havia linha de ordenha estabelecida para animais com alta CCS. Resíduos de leite foram observados nos equipamentos de ordenha e no tanque de expansão, e os insufladores estavam desgastados e apresentavam rachaduras.

Nenhuma das propriedades possuía um programa de controle da mastite ou acompanhamento adequado quanto ao uso de medicamentos veterinários. Os resultados obtidos do isolamento de agentes causadores de mastite (Tab. 2) demonstram contaminação por agentes causadores de mastite contagiosa. A fonte primária dessas infecções é o úbere de vacas infectadas, e a disseminação acontece a partir de quartos mamários infectados para sadios no momento de ordenha. Para o controle e a eliminação da mastite, todas as vacas devem ser tratadas na secagem, e vacas com infecção crônica devem ser descartadas (Santos e Fonseca, 2007). Neste estudo, foi detectado número elevado de animais que iniciavam a lactação com alta CCS, que persistia durante a lactação, indicando que os medicamentos utilizados na secagem dos animais não foram eficientes.

Tabela 2. Principais agentes causadores da mastite isolados de amostras de leite individual em cinco propriedades (A, B, C, D e E) localizadas em Pitangueiras, Paraná, janeiro de 2010

\begin{tabular}{cc}
\hline Propriedades & Micro-organismos isolados \\
\hline A & $\begin{array}{r}\text { Staphylococcus aureus } \\
\text { Staphylococcus } \text { spp. } \\
\text { coagulase negativa }\end{array}$ \\
B & $\begin{array}{r}\text { Staphylococcus } \text { spp. } \\
\text { coagulase negativa }\end{array}$ \\
D & $\begin{array}{c}\text { Staphylococcus } \text { spp. } \\
\text { coagulase negativa }\end{array}$ \\
E & Streptococcus agalactiae \\
\hline
\end{tabular}

Com base nos resultados obtidos durante a avaliação inicial das propriedades, os produtores receberam e adotaram as seguintes orientações: a) manutenção e higienização dos equipamentos de ordenha com detergente alcalino clorado (130ppm); detergente ácido duas vezes por semana, conforme instruções do fabricante; c) lavagem das mãos dos ordenhadores a cada lote ordenhado com água e sabão, seguida de antisséptico à base de cloro; d) realização do teste da caneca de fundo preto; e) lavagem dos tetos com água somente em caso de muita 
sujidade; f) pré-dipping com solução clorada a $750 \mathrm{ppm}$ e secagem dos tetos após 30 segundos, com papel-toalha individual; g) realização de pós-dipping com produto à base de ácido láctico; h) estabelecimento de linha de ordenha de acordo com a CCS; i) ordenha de animais recém-paridos no final e desinfecção do conjunto de ordenha com cloro; j) fornecimento de volumoso logo após a ordenha; k) tratamento dos animais com mastite na secagem por meio de antibioticoterapia.

Foi estabelecido um protocolo como critério de tratamento na secagem dos animais, utilizando-se antibiótico intramamário à base de cefalônio anidro, selecionado com base nos resultados dos antibiogramas. $\mathrm{Na}$ propriedade $\mathrm{A}$, o uso da vacina Hipramastivac ${ }^{\circledR}$ foi associado à secagem, específico para mastite causada por Staphylococcus aureus e Escherichia coli.

As propriedades foram monitoradas por um período de sete meses, e os resultados obtidos demonstram redução na contagem de células somáticas e na contagem bacteriana total do leite de conjunto de todas as propriedades avaliadas (Tab. 3).

Tabela 3. Contagem de células somáticas $(\mathrm{CCS})\left(\mathrm{x} 10^{3} \mathrm{CS} / \mathrm{mL}\right)$ e contagem bacteriana total $(\mathrm{CBT})\left(\mathrm{x} 10^{3}\right.$ $\mathrm{UFC} / \mathrm{mL}$ ) em cinco propriedades (A, B, C, D e E) leiteiras localizadas em Pitangueiras, Paraná, em janeiro de 2010, antes da aplicação de boas práticas, e em agosto de 2010, após a aplicação de boas práticas

\begin{tabular}{ccccccc}
\hline \multirow{2}{*}{ Propriedade } & \multicolumn{2}{c}{ Janeiro/ 2010 } & \multicolumn{2}{c}{ Agosto/ 2010 } & \multicolumn{2}{c}{ Redução (\%) } \\
\cline { 2 - 6 } & CCS & CBT & CCS & CBT & CCS & CBT \\
\hline A & 1882 & 548 & 208 & 23 & 88,9 & 95,8 \\
B & 2205 & 2904 & 402 & 09 & 81,7 & 99,6 \\
C & 1116 & 600 & 482 & 79 & 56,8 & 86,8 \\
D & 1974 & 674 & 574 & 93 & 70,9 & 86,2 \\
E & 2189 & 2097 & 588 & 33 & 73,1 & 98,4 \\
Média & 1873,2 & 1364,6 & 450,8 & 47,4 & 74,3 & 93,4 \\
\hline
\end{tabular}

Antes da adoção de boas práticas, a média de CCS e CBT das cinco propriedades avaliadas era de $1,87 \times 10^{6} \mathrm{CS} / \mathrm{mL}$ e $1,36 \times 10^{6} \mathrm{UFC} / \mathrm{mL}$, respectivamente. Observa-se que houve redução média de $74,3 \%$ para CCS e de $93,4 \%$ para CBT.

A significativa melhoria de CCS, possivelmente, foi decorrente da utilização de antibiótico na secagem dos animais, que, de acordo com a Mesquita e Bueno (2005), é o procedimento mais eficiente no controle da mastite subclínica. $\mathrm{Na}$ propriedade $\mathrm{A}$, onde foi utilizada a vacinação dos animais, ocorreu maior redução na CCS do leite de conjunto, com média de $88,9 \%$. Segundo Müller (2002), investigações com o uso da vacina apresentaram resultados promissores em relação ao controle das mastites causadas por $S$. Aureus.

Todas as propriedades conseguiram atingir os parâmetros estabelecidos para CBT exigidos pelo Programa Leite das Crianças (Paraná, 2009) após as mudanças de manejo e aplicação correta de boas práticas de ordenha. Este resultado é semelhante ao obtido em outros estudos, que avaliaram a implementação de boas práticas de ordenha (Fagan et al., 2005; Valin et al., 2009; Matsubara et al., 2011).Contudo, a redução de CCS aos valores exigidos pelo programa foi obtida apenas pelas propriedades A, B e C (Tab. 4), embora as propriedades $\mathrm{D}$ e $\mathrm{E}$ tenham atingido valores muito próximos ao exigido. Schaik et al. (2005) estudaram diversos fatores e sua influência na CBT e na CCS e relataram que as duas contagens não estão necessariamente relacionadas.

Enquanto a CBT é uma medida direta de contaminação do leite, a CCS é uma medida indireta de inflamação ou infecção da glândula mamária. Assim, alguns fatores relacionados ao animal também atuam de forma importante e podem explicar por que um produtor pode ser capaz de controlar a CBT e não a CCS (Schaik et al., 2005). Falhas na implantação de boas práticas de ordenha e nas mudanças sugeridas no manejo também podem explicar essa diferença; além disso, medidas mais drásticas, como o 
descarte de animais com mastite crônica, podem ser necessárias (Fagundes et al., 2006; Santos e Fonseca, 2007), mas não foram realizadas no presente estudo.

O impacto financeiro, causando aumento da renda do produtor, é um importante fator de convencimento na recomendação da implantação de boas práticas e de um programa de controle da sanidade da glândula mamária. Segundo Philpot e Nicherson (2002), os investimentos no controle da mastite acarretam menor número descartes prematuros de animais, diminuição dos casos clínicos, redução do descarte de leite, diminuição dos gastos com medicamentos e com mão de obra adicional.
O laticínio que recebia o leite pagava pela qualidade. Para leite com CCS dentro do limite de 500 mil, eram pagos três centavos adicionais, e para o leite que se enquadrava nas exigências da CBT, dois centavos, totalizando cinco centavos por litro de leite para as propriedades que se enquadravam nas duas exigências (propriedades A, B e C). Para aquelas que atingiram os limites máximos (propriedades D e E), pagavam-se dois centavos (Tab. 4). As mudanças adotadas pelas propriedades avaliadas geraram aumento na renda mensal, que variou de $\mathrm{R} \$ 120,00$ a $\mathrm{R} \$ 828,00$, de acordo com a produção de cada propriedade (Tab. 4).

Tabela 4. Influência do pagamento (em reais $\mathrm{R} \$$ ) por qualidade na renda dos produtores de leite de cinco propriedades (A, B, C, D e E) leiteiras localizadas em Pitangueiras, Paraná, em agosto de 2010

\begin{tabular}{lccccc} 
& $\mathrm{A}$ & $\mathrm{B}$ & $\mathrm{C}$ & $\mathrm{D}$ & $\mathrm{E}$ \\
\hline $\begin{array}{l}\text { Sem adicional de qualidade } \mathrm{R} \$ 0,66 / \mathrm{L} \text { de } \\
\text { leite }\end{array}$ & 7.920 & 5.940 & 11.286 & 8.514 & 3.960 \\
$\begin{array}{l}\text { Com adicional de qualidade } \mathrm{R} \$ 0,71 \text { ou R } \$ \\
\begin{array}{l}\text { 0,68/L de leite* } \\
\text { Ganho mensal }\end{array}\end{array}$ & 8.520 & 6.390 & 12.114 & 8.772 & 4.080 \\
$\begin{array}{l}\text { adicional } \\
\text { Ganho anual } \\
\text { adicional }\end{array}$ & 600 & 450 & 828 & 258 & 120 \\
*adicional de três centavos para CBT<500 mil UFC/mL e dois centavos para CCS < 500 mil CS/mL &
\end{tabular}

\section{CONCLUSÕES}

O estabelecimento de boas práticas de ordenha, manutenção e higienização dos equipamentos e o monitoramento da sanidade da glândula mamária permitiram a redução na CBT e na contagem de células somáticas em todas as propriedades avaliadas. Embora todas as propriedades tenham atingido os requisitos estabelecidos pela legislação quanto à CBT, apenas três o fizeram quanto à CCS. Os resultados obtidos evidenciam a importância do pagamento por qualidade do leite como forma de motivação dos produtores para a melhoria da qualidade do leite produzido.

\section{REFERÊNCIAS}

BELOTI, V.; RIBEIRO JÚNIOR, J.C.; TAMANINI, R. et al. Qualidade microbiológica e físico-química do leite cru refrigerado produzido no município de Sapopema/PR. R. Cient. Eletr. Med. Vet., v.16, p.2, 2011.
BRASIL. Ministério da Agricultura, Pecuária e Abastecimento. Instrução Normativa $n .51$ de 18 de setembro de 2002. Regulamento Técnico de Produção, Identidade e Qualidade de Leite Tipo A, Tipo B, Tipo $\mathrm{C}$ e Cru refrigerado. Diário Oficial [da] República Federativa do Brasil, Brasília, 29 set. 2002. Seção 1, p.13.

BRASIL. Ministério da Agricultura, Pecuária e Abastecimento. (2002) Instrução Normativa ${ }^{\circ} 32$, de 30 de junho de 2011. Diário Oficial [da] República Federativa do Brasil, n.125, Seção 1, p. 4, 01 de julho de 2011.

FAGAN, E.P.; BELOTI, V.; BARROS, M.A.F. et al. Avaliação e implantação de boas práticas nos principais pontos de contaminação microbiológica na produção leiteira. Semina: Cienc. Agr., v.26, p.83-92, 2005.

FAGUNDES, C.M.; FISCHER, V.; SILVA, W.P. et al. Presença de Pseudomonas spp. em função de diferentes etapas da ordenha com distintos manejos higiênicos e no leite refrigerado. Cienc. Rural, v.36, p.568-572, 2006. 
FAO. Food and Agriculture Organization of the United Nations. Food and Agricultural commodities production. Disponível em: <http://faostat.fao.org/site/339/default.aspx>. Acessado em: 02 out. 2011.

HIRSH, D.C.; ZEE, Y.C. Microbiologia Veterinária. Rio de Janeiro: Guanabara Koogan, 1999. 446 p.

HOLT, J.G.; KRIEG, N.R.; SNEATH, P.H.A. et al. Bergey's Manual of Determinative Bacteriology. 9.ed. Baltimore: Williams \& Wilkins, 1994. 787p.

IBGE. Instituto Brasileiro de Geografia e Estatística. Estados. Disponível em:< http://www.ibge.gov.br/estadosat/temas.php?sigla=pr \&tema=pecuaria2009> . Acessado em: 28 mai. 2011.

KONEMAN, E.W.; ALLEN, S.D.; JANDA, W.M. et al. Diagnóstico Microbiológico. 5.ed. Montevideo: Panamericana, 1999. $1432 \mathrm{p}$.

MATSUBARA, M.T.; BELOTI, V.; TAMANINI, R. et al. Boas práticas de ordenha para redução da contaminação microbiológica do leite no agreste Pernambucano. Semina Cienc. Agrar., v.32, p.277286, 2011.

MESQUITA, A.J.; BUENO, V.F.F. Estudos sobre a qualidade do leite no Estado de Goiás. In: CARVALHO, L.A.; ZOCCAL, R.; MARTINS, P.C. et al. Tecnologia e gestão na atividade leiteira. Juiz de Fora: Embrapa Gado de Leite, 2005. p.99-103.

MÜLLER, E.E. Qualidade do leite, células somáticas e prevenção da mastite. In: SIMPÓSIO SOBRE SUSTENTABILIDADE DA PECUÁRIA LEITEIRA NA REGIÃO SUL DO BRASIL, 2., 2002. Toledo PR. Anais do II Sul- Leite: Simpósio sobre Sustentabilidade da Pecuária Leiteira na Região Sul do Brasil. Maringá: NUPEL, agosto de 20002.206-2117. Disponível em: <http://www.nupel.uem.br/qualidadeleitem.pdf>. Acessado em: 2 out. 2011.

NERO, L.A.; MATTOS, M.R.; BELOTI, V. et al. Leite cru de quatro regiões leiteiras brasileiras: perspectivas de atendimento dos requisitos microbiológicos estabelecidos pela Instrução Normativa 51. Cienc. Tecnol. Aliment., v.25, p.191-195, 2005.
PARANÁ. Instrução Normativa $\mathrm{N}^{\circ}$ 01/2009 do Programa Leite das Crianças - Redução da Deficiência Nutricional das Crianças, Gestantes e Nutrizes. 04 de fevereiro de 2009. Curitiba, 2009. Disponível em: <http://www.leite.pr.gov.br/arquivos/File/legislacao/I NSTRUCAO_NORMATIVA_N_01_2009_ver3.pdf>. Acessado em: 10 mai 2011.

PHILPOT, N.W.; NICKERSON, S.C. Vencendo a luta contra a mastite. Piracicaba: Westfalia Surge/Westfalia Landtechnik do Brasil, 2002. 192p.

SANTANA, E.H.W.; BELOTI, V.; BARROS, M.A.F. et al. Contaminação do leite em diferentes pontos do processo de produção: I. Microrganismos aeróbios mesófilos e psicrotróficos. Semina Cienc. Agrar., v.22, p.145-154, 2001.

SANTOS, M.V.; FONSECA, L.F.L. Estratégias para Controle de Mastite e Melhoria da Qualidade do Leite. São Paulo: Manole, 2007.

SCHAIK, G.V.; GREEN, L.E.; GUZMÁN, D. et al. Risk factors for bulk milk somatic cell counts and total bacterial counts in smallholder dairy farms in the 10th region of Chile. Prev. Vet. Med., v.67, p.1-17, 2005.

SILVA, L.C.C.; BELOTI, V.; TAMANINI, R. et al. Rastreamento de fontes da contaminação microbiológica do leite cru durante a ordenha em propriedades leiteiras do Agreste Pernambucano. Semina Cienc. Agrar., v.32, p.267-276, 2011.

USDA. United States Department of Agriculture. Foreign Agricultural Service. (jul 2011) Disponível em:

<http://www.fas.usda.gov/psdonline/circulars/dairy.pd f>. Acessado em: 02 out. 2011.

VALIN, V.M.; BELOTI, V.; BATTAGLINI, A.P.P. et al. Melhoria da qualidade do leite a partir da implantação de boas práticas na ordenha de 19 municípios da região central do Paraná. Semina Cienc. Agrar., v.30, p.181-188, 2009. 